NCy 11

ANTICANCER ACTIVITY OF NEW ALKYLLYYSOPHOSPHOLIPIDDERIVATES

C.Muschiol, M.A.Berger, D.Schmäh, C.Unger, H.J.Eibl 1-Octadecyl-2-methyl-rac-glycero-3-phosphocholine (1) belongs to a new class of antineoplastic agents and has shown dose-dependent activity in methytnitrosourea (MNU)-induced rat mammary carcinoms. The cytotoxic effect of these compounds on tumor cells has been related to the deficiency of 1-0-alkyl-cleavage enzyme. Therefore it was intented to develop analogous compounds which are better substrates to this enzyme to facilitate defoxification in normal cells. The following compounds have bcen tested (treatment $5 \times$ /week for 5 wocks, p.o.) in SD-rats bearing methylnitrosourea (MNU)-induced mammary carcinoma in comparison to (1).

2)1-0-Octadecylpropanediol-(1.3)-phoshocholine

3) 1-O-Hexadecylpropanediol-(1.3)-phosphocholine

4)1-O-Hexadecylpropanediol-(1.2)-phosphocholine

5) 1-O-Octadecyl-sn-glycero-3-phosphotrimethylammoniumhexanol 6) Hexadecylphoshocholine. Compounds (C) $1,2,3$ and 5 were given in three doses $(115,77,51 \mu \mathrm{mol} / \mathrm{kg}$ bw), $C 3$ in two doses $(115,77 \mu \mathrm{mol} / \mathrm{kg} \mathrm{bW})$ and $C 6$ in one dose $(115 \mu \mathrm{mol} / \mathrm{kg}$ bw). Therapeutic effect was evaluated by measuring tumor volumes of treated and control animals (T/C\%) and tumor numbers per rat (TN), loxicity by $x_{\text {mortality }}\left({ }_{6} M\right)$ and median body weight difference (\%BWD). Results: $C 2,3$ and 5 which were shown to be befter substrates for the 1-0-alkyl-cleavage enzyme compared to 1 exhibited no therapeutic effect, only $\mathrm{C} 3$ showed a markedly decreased toxicity. C 4 given in the highest dose $(115 \mu \mathrm{mol} / \mathrm{kg})$ had a comparable therapeutic effect as 1 given in a dose of 77 $\mu \mathrm{mol} / \mathrm{kg}$ ( $T / \mathrm{C} 444$ vs 46 ). The toxicity was considerable lower than the toxicity of 1 in the highest dose. C 6 which is not a 0 -alkyl-ether and therefor no substrate for the detoxifying enzyme showed the highest antineoplastic activity in our model; following data were obtained, comparing equimolar doses of 6 and $1: T / C \% 1.1$ and 23 , TN $1(0-1)$ and $6(5-9)$. $\% B W D-6.6$ and -3.2 XM 47 and 64 . These results indicate, that the chemical modifications that led to better substrates of the 1-O-alkyl-cleavage enzyme were not correlated with higher antineoplastic efficacy than 1 in the model used.

Institut für Toxikologie und Chemotherapie, Im Neuenheimer Feld 280, D-69 Heidelberg

\section{NCy 12}

NEW DRUGS IN TUMOUR THERAPY:

1-ALKYL-PROPANDIOL (1.2) PHOSPHOCHOLINES

C. Unger, D.-J. Kim, M.R. Bercer, G.A. Nagel and H. Eibl

Aim of research: It was the aim of this study to look for antineoplastic agents with a selective toxicity against tumour cells. This goal may be achieved with the help of phospholipid-metabolizing enzymes. As described in the literature for the 1-O-alkyl cleavage enzyme (J.F. Soodsma et al., Cancer Res. 30, 309, 1970), there are quantitative differences in the enzyme equipment between tumour tissue and normal cells. "Tailor-made" (alkyl)-lysophospholipids with substrate properties for the cleavage enzyme are expected to be less toxic to normal cells than the most studied 1-octadecy1-2-o-methyl-rac-glycero-3-phosphocholine, which is no substrate for this enzyme ( $C$. Inger et al.." Cancer Res. 45, 616, 1985).

Methods: Cytotoxic effects of the new agents were studied against different leukaemic cells, in comparison to a fibroblastic cell line, by inhibition of (3H)thymidine incorporation into DNA, and the trypan blue dye exclusion test.

Results: The compound inhibited the in vitro incorporation of tritiated thymidine into HL 60, Raji and $\mathrm{K} 562$ human leukaemic cell lines. This activity was well correlated with trypan blue dye exclusion. Complete cell destruction was achieved with $2.5 \mathrm{\mu g} / \mathrm{ml}$ (HL 60), $12 \mu \mathrm{g} / \mathrm{ml}$ (Raji) and $25 \mu \mathrm{g} / \mathrm{ml}$ (K 562 ) after an incubation time of about $72 \mathrm{hrs}$ - no toxic effects on fibroblasts up to $40 \mu \mathrm{g} / \mathrm{ml}$. In addition, the first results indicate that 1-hexacecyl-propandiol-(1.2)-phosphocholine is an active compound in the treatment of nitrosourea-induced mammary carcinomas of the rat.

Conclusions: From our results we learnt that 1-hexadecylpropandiol-(1.2)-phosphocholine is a powerful new antineoplastic agent with remarkable differences in the toxic concentrations between tumour and normal celis.

Zentrum Innere Medizin, Abt. Hämatologie/onkologie, Robert-Koch-Str. 40, D-3400 Göttingen
NCy 13

(ALKYL)-LYSOPHOSPHOLIPIDS IN TUMOUR THERAPY: A NEW CONCEPT H. Eibl and C. Unger

Aim of research: (Alkyl)-lysophosphocholines, especially 1-o-octadecy 1-2-o-methyl-rac-glycero-3-phosphocholine, have strong antineoplastic activity as demonstrated by Munder, Westphal and Fischer. This property was mainly attributed to the stimulation of the immune system and possibly to a cytotoxic effect of the compounds (H.U. Weltzien and P.G. Munder, in: (U.K. Mangold and F. Paltauf, eds.) Ether Lipids, Acadenic Press, New York, 277, 1983). With respect to the cytotoxic properties, we observed in our studies that incubation of Raji cells with different (alkyl)-lysophospholipids of almost identical haemolytic activity resulted in a very differentiated toxicity against these cells. This result is not understood on a molecular leve1. Therefore, we performed experiments to explore the mechanisms which lead to the differentiated toxicity of (alkyl)-iysophospholipids with very similar properties.

Methods: Phospholipid-metabolizing enzymes were studied in vitro and in vivo by using spectrophotometric tests and incubations with radiolabeliled (alkyl)-lysophospholipids for the analysis of the metabolic fate of these molecules in the cell (C. Unger et al., Cancer Res. 45, 616, 1985: E.A.M. Fleer et al., Chem. Phys. Iipids, in press).

Results and conclusions: We have shown that the actual (alkyl)-Iysophospholipids in concentrations which lead to complete destruction of the Raji cells are not toxic. However, metabolites generated by the action of a phospholipase C-like enzyme are toxic to the cells. On the basis of a deep understanding of the metabolic events which take place in the living cell, we have developed a new concept which leads to a preferential destruction of tumour cells in the presence of normal ones.

Max-Planck-Institut für biophysikalische Chemie. Am Faßberg, D-3400 Göttingen

\section{NCy 14}

METABOLITES UF 5-FLUURUURACIL IN HUMAN PLASMA ANU URINE

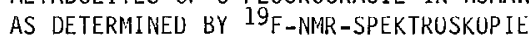

R.E. Port, W.E. Hull, K. Herrmann, B. Britsch, W. Kunz 5-Fluorouracil (FU) and its catabolites have been deter mined in plasma and urine of metastatic colon cancer patients after intravenous infusion of $6 \mathrm{U}-230$ moles $\mathrm{FU} / \mathrm{kg}$ body weight by ${ }^{19} \mathrm{~F}-\mathrm{NMR}-\mathrm{spect}$ roscopy at $470 \mathrm{MHz}$. The lower detection limit for quantitative analysis with 12 hours of data acquisition was ca. 3 umoles FU/l. In plasma FU shows in several cases two signal components. The major signal represents $F U$ in rapid exchange between free and protein-bound states; a very broad signal apparently comes from a fraction of FU that is tightly bound to protein. None of the FU catabolites show such an interaction with protein. With the doses used FU disappears from plasma within 60-90 min. The first catabolite dihydrofluorouracil (DHFU) appears in plasma within 5 min and exhibits a steadystate concentration of ca. 10-30 $\mu \mathrm{M}$ throughout the 5-90 min observation period. Fluoroureidopropionic acid (FUPA) shows a steady-state concentrat ion similar to that of UHFU, while $\alpha-f l u o r o-\beta-a l a n i n e$ (FBAL) increases to a dose-dependent maximum of $50-15 \mathrm{U}$ $\mu M$ at 60-90 min. Elevated levels of free fluoride anion $\left(\mathrm{F}^{-}\right)$were observed in plasma for 7 out of 17 cases. Urine samples showed that 3 to $30 \%$ of the $\mathrm{FU}$ dose was excreted after two hours $(n=18)$ either unchanged ( 1 to $14 \%$ of dose) or as catabolites (mainly FBAL, 0.3 to $17 \%$ of dose). FBAL was still excreted on the third day after infusion $(27-55 \mu$ moles $/ 24 \mathrm{hr}, \mathrm{n}=3)$. In 4 cases where urine was collected for 3 days after treatment $\mathrm{F}^{-}$showed a maximum on the first day after FU infusion. Plasma concentrations of catabolites are less than proportional to FU dose, indicating that the reported reciprocal dose dependence of FU plasma clearance is caused by saturation of catabolism. $F^{-}$and possibly undetected amounts of FBAL metabolites should be considered as potential mediators of FU toxicity.

Institut für biochemie, Veutsches krebsforschungszentrum, Im Neuenheimer Feld 280, U-6900 Heidelberg 1 